\title{
CONFORMATION OF SOME CARBOXYLIC ACIDS AND THEIR DERIVATIVES
}

\author{
J. A. Kanters, J. Kroon, A. F. Peerdemait and J. C. Schoone. \\ Laboratorium voor Kristalchemic, Rijksuniversiteit Litrecht, The Netherlands \\ (Received 10 December 1966: accepied for publication 15 February 1967)
}

\begin{abstract}
Abatract-The conformation in the crystalline state of some aliphatic carboxylic acids and thetr derivatives has been analysed. This analysis, basod upon the results of structure determinations by means of X-ray diffraction, seems to support the concept that the conformation of a molecule is governed chiefly by intramolecular interactions.
\end{abstract}

\section{INTRODUCTION}

In this article, the rotational arrangement (conformation') of substituents about a $\mathrm{C}\left(\mathrm{sp}^{3}\right)-\mathrm{C}\left(\mathrm{sp}^{2}\right)$ bond in aliphatic carboxylic acids is discussed. Different groups of these acids pass in review and attention is paid to the conformational aspects as well as to the bond lengths and bond angles of the acetic acid group concerned.

After numerous investigations of the structures of carboxylic acids and their derivatives in the crystalline state by means of X-ray diffraction it is possible to point out some common features in the molecular structures of these compounds. In general the same conformation of a definite molecule is found again and again in crystal structures. This conformational stability is manifest in various structures independent of the space group to which the crystal belongs and of the ionic or molecular character or of the hydrogen bond scheme of the structurc. This seems to justify the concept that the realization of a certain conformation in the crystalline state is inherent to the free molecule itself, intramolecular forces dominating over intermolecular interactions.

It is a well-known fact that in the case of a rotation about a $\mathrm{C}\left(\mathrm{sp}^{3}\right)-\mathrm{O}\left(\mathrm{sp}^{3}\right)$ bond the energetically most favourable conformation is the staggered one. The $\mathrm{C}\left(\mathrm{sp}^{3}\right)$ $\mathrm{C}\left(\mathrm{sp}^{2}\right)$ conformation in carboxylic acids-the double bonded carboxyl oxygen atom being in an eclipsed position with the $\alpha$-substituent or $\beta$-carbon atom is compatible with such a staggered conformation if we are to accept Paulings bent bond idea of the double bond. 2.3

\section{Monocarboxylic acids}

As may be evident from Table 1 , the $\beta$-carbon in the acids is fairly coplanar with the atoms of the acetic acid group. The $\mathrm{C}_{3}-\mathrm{O}_{2}$ distance, being reasonably constant. is no less than about $0.4 \AA$ shorter than a normal van der Waals contact. ${ }^{2}$ Owing to the smaller $\mathrm{O}_{1} \mathrm{C}_{1} \mathrm{C}_{2}$ angle this distance would be greatly decreased if $\mathrm{O}_{1}$ were in the eclipsed position to the $\beta$-carbon atom (approximately $0.15 \mathrm{~A}$ ).

' E. L. E:liel, Stereochemistry of Carbon Compounds Chap. 6: p. 133. McGraw-Hill. N.Y. (1962)

2 L. Pauling. The Noture of the Chemical Bond. Cornell University Press, N.Y. (1960).

'I. Pauling Proc Nat. Acad Sci. U.S.A. 4. 211 (1958). 
Noteworthy is the difference between the average $\mathrm{CCC}$ angle in the carbon chain and the angle $\mathrm{C}_{1} \mathrm{C}_{2} \mathrm{C}_{3}$ that partly determines the $\mathrm{C}_{3}-\mathrm{O}_{2}$ distance: the latter angle is significantly larger than the former.

When no $\alpha$-substituent and no $\beta$-carbon atom is present (acetic acid) one hydrogen atom is found to be in the eclipsed position to the carbonyl oxygen atom."

\section{Dicarboxylic acids}

Experimental data of dicarboxylic acids are listed in Table 2. In this series there is a striking alternation in the rotational position of the carboxyl groups with respect to the carbon chain plane, which is reflected in the saw-tooth m.p. curve. ${ }^{9}$ This alternation is the result of the coupling of carboxyl groups, which in the odd members of the series is only possible if the carboxyl groups are rotated several degrees out of the carbon chain.

It is interesting to note the existence of high temperature modifications of the odd members. ${ }^{16}$ In these modifications the molecules have lost their symmetry (dyad axis). one carboxyl group being coplanar with the carbon chain plane, whereas the other one, in order to make carboxyl groups couple. makes a yet larger angle with this plane.

The first term of this series, malonic acid ${ }^{10}$ has deliberately been left out of Table 2 , since the short distance between the terminal groups excludes planarity. A compromise is attained in such a way that one carboxyl group is in the plane of the carbon atoms, the other being turned perpendicular to it.

\section{$x$-Hydroxycarboxylic acids}

The $\alpha$-hydroxyl group is seen to take over the role from the $\beta$-carbon atom such. that this oxygen atom is more or less in the carboxyl group plane (Table 3 ). The mean value of the $\mathrm{C}_{3} \cdots \mathrm{O}_{2}$ distance is about $0.25 \mathrm{~A}$ lower than a normal van der Waals contact. ${ }^{2}$

In acids with an asymmetric $x$-carbon atom the rotational angle of the plane of the carboxyl group with respect to the plane of the carbon chain has been provided with a sign. No significant preference for a definite rotational sense has been found.

4. A. Kanters and J. Kroon, unpublished work (1965).

${ }^{3}$ F. J. Strieter and D. H. Templeton. Acta Cryst. 15. 1233 (1962).

- Ibid. 1240.

'R. F. Scheuermann and R. L. Sass, Acta Cryst. 15, 1244 (1962).

- G. A. Jeffrey and M. Sax, Acla Cryst. 16. 1196 (1963).

- C. H. MacGillavry. G. Hoogschugen and F. L. J. Sixma, Rec. Trav. Chim. 67, 867 (1948).

10 J. A. Goedkoop and C. H. MacGillavry, Acta Cryst. 10, 125 (1957)

11 J. S. Broadley, D. W. J. Cruickshank. J. D. Morrison J. M. Robertson and H. M. M. Shearer. Proc. Roy. Soc. A, 250, 441 (1959)

12 J. D. Morrison and J. M. Robertson, J. Chem. Soc. 987 (1949).

$13 \mathrm{~J}$. Housty and M. Hospital. Acta Cryst. 17. 1387 (1964).

14 J. D. Morrison and J. M. Roberison. J. Chem. Soc 993 (1949).

is J. D. Morrison and J. M. Roberison. J. Chem. Soc. 1001 (1949).

16 M. I. Kay and L. Katz. Acta Cryst 11. 289 (1958).

1) A. J. van Bommel, Thesis, Utrecht (1956).

1. A. J. J. Sprenkels. Thesis. Utrechi (1956).

10 G. A. Bootsma and J. C. Schoone. Acra Cryst. 22, 522 (1967).

${ }^{20}$ G. S. Parry. Acta Cryst. 4. 131 (1951). 
The largest deviation from planarity of the $x$-hydroxyacetic acid groups was found in tartronic acid. ${ }^{21}$ As in malopnic acid, intramolecular steric hindrance prevents the coplanarity of the relevant atoms, the distance between the $\mathrm{OH}$ oxygen atoms of the carboxyl groups being $2.92 \AA$ In fluoromalonic acid ${ }^{23}$ the planarity of both fluoroacetic acid groups is much better, however, in spite of the fact that the distance mentioned above $(2.92 \mathrm{~A})$ remains unaltered.

It must be mentioned that in $\alpha$-hydroxycarboxylic acids a few exceptions have been found to the rule that the double bonded oxygen atom of the carboxy! group is situated at a shorter distance from the $x$-substituent. ${ }^{19}$ The reason for this is not quite clear. A common feature in these acids is the enlargement of the two OCC bond angles at the side of the short contact between the two $\mathrm{OH}$ oxygen atoms and the participating in very strong hydrogen bonds.

Salts of $x$-hydroxycarboxylic acids

In salts the conformation is the same as in the $x$-hydroxycarboxylic acids. The most peculiar phenomenon is the inequivalency of the two OCC bond angles in the carboxyl group. The enlargement of the angle situated at the side of the $\alpha$-substituent is significant. Moreover, the differences in the $\mathrm{C}-\mathrm{O}$ bond lengths also warrant the idea that. here too. the oxygen atom in the bond with the greater double bond character is in an eclipsed position to the aliphatic $\mathrm{OH}$ group.

\section{Additional remarks}

It should be noted that the preference of the $\alpha \cdot \mathrm{OH}$ group over the $\beta$-carbon atom for the carboxyl plane has nothing to do with the existence of an intramolecular hydrogen bond. Such a 5 -membered ring (the $\mathbf{H}$-atom included) is highly unfavourable : ${ }^{2}$ the distance of the $\mathrm{H}$-atom to the carbonyl oxygen atom is fairly large : even in the most propitious position the hydrogen atom is not very well directed towards the oxygen lone pair electrons and finally a hydrogen bond thus conceived would be far from linear. In tartronic acid, for example, such a bond is completely absent, as appears from X-ray ${ }^{21}$ and IR data. in spite of the fact that the $\mathrm{H}$-atom is not involved in any other hydrogen bond.

Steric hindrance will also decrease the acceptor potentialities of the carboxyl oxygen atom that is at a short distance from the $\alpha$-substituent or the $\beta$-carbon atom. One of the two lone pairs of this carboxyl oxygen atom is directed backwards and has its greatest electron density in the plane of the carboxyl group where the $x$-substituent or the $\beta$-carbon atom is also situated. Thus it seems unprofitable for this lone pair to become involved in -a hydrogen bond, the $\alpha$-substituent or the $\beta$-carbon atom preventing any oxygen atom from coming into closer contact with the carbonyl oxygen atom in that direction.

In conclusion the statement seems justified that from the point of view of hydrogen bonding the coplanarity of the acetic acid group with the $x$-substituent or the $\beta$-carbon atom is unfavourable. All the more reason to disparage intermolecular interactions when considering the conformation of the compounds discussed above.

21 B. P. van Eijck. J. A. Kanters and J. Kroon. Acta Cryst. 19. 435 (1965).

22 L. Golic and J. C. Speakman. J. Chem. Soc 2521 (1965).

$\therefore$ J. A. Kanters. J. Kroon. G. Roclofsen and J A. Vliegenthart, to be published (1967).

24 J. Kroon. A. F. Peerdeman and J. M. Bijvoet. Acta Cryst. 19. 293 (1965).

2s R H Colion and D. F. Henn. Acta Cryst. 18. 820 (1965). 


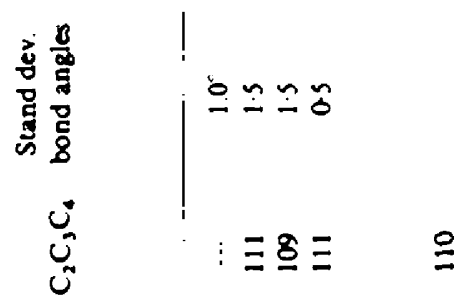

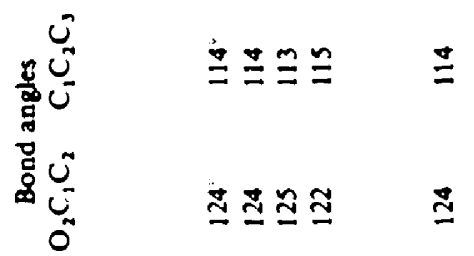
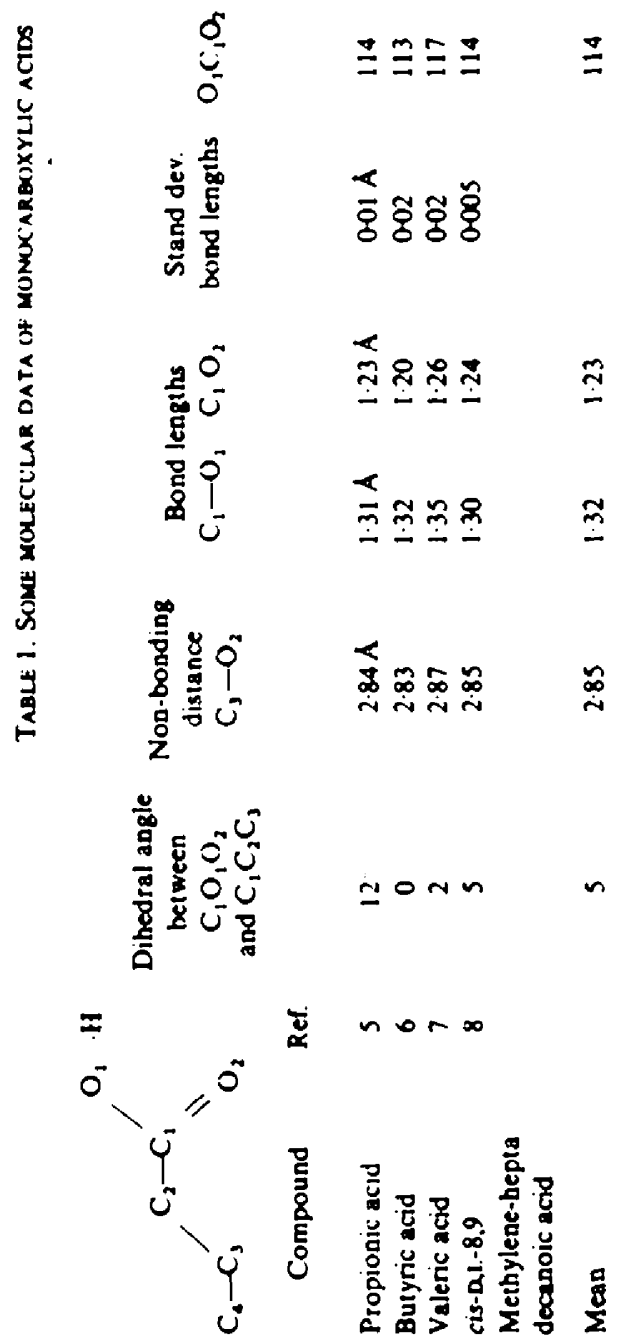


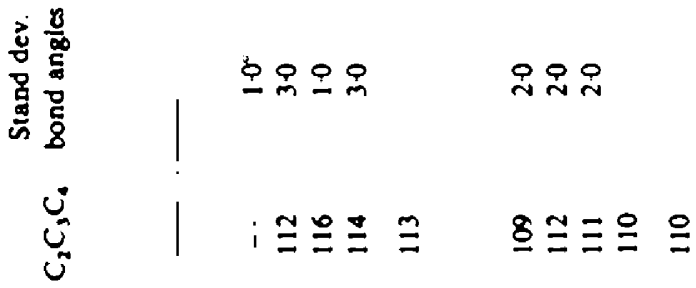

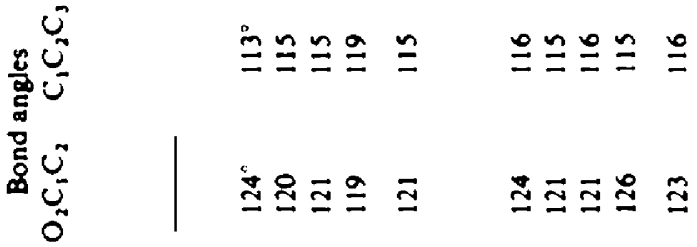

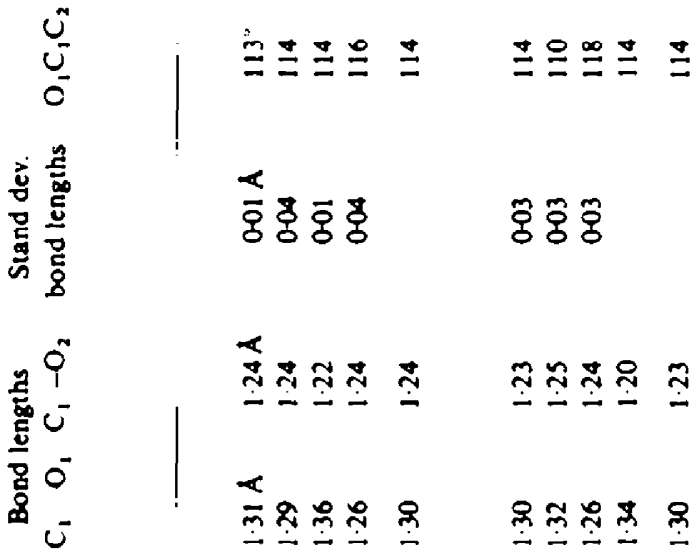

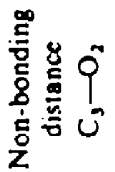

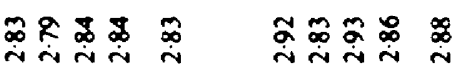

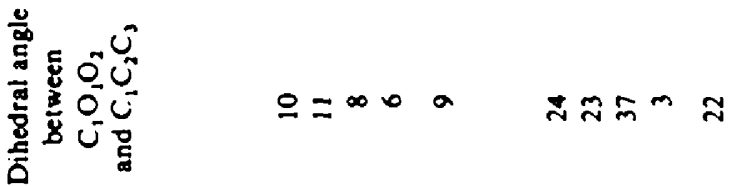

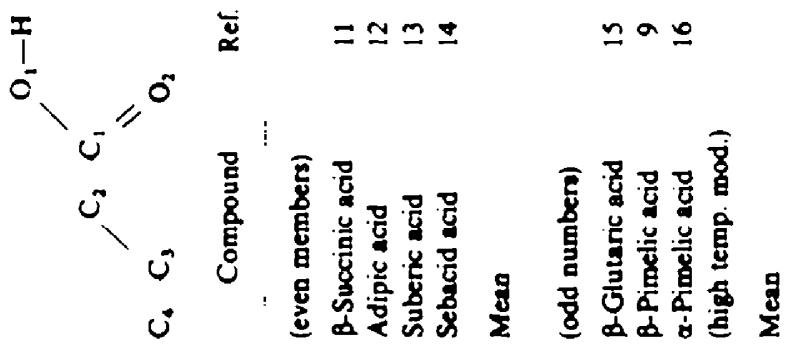




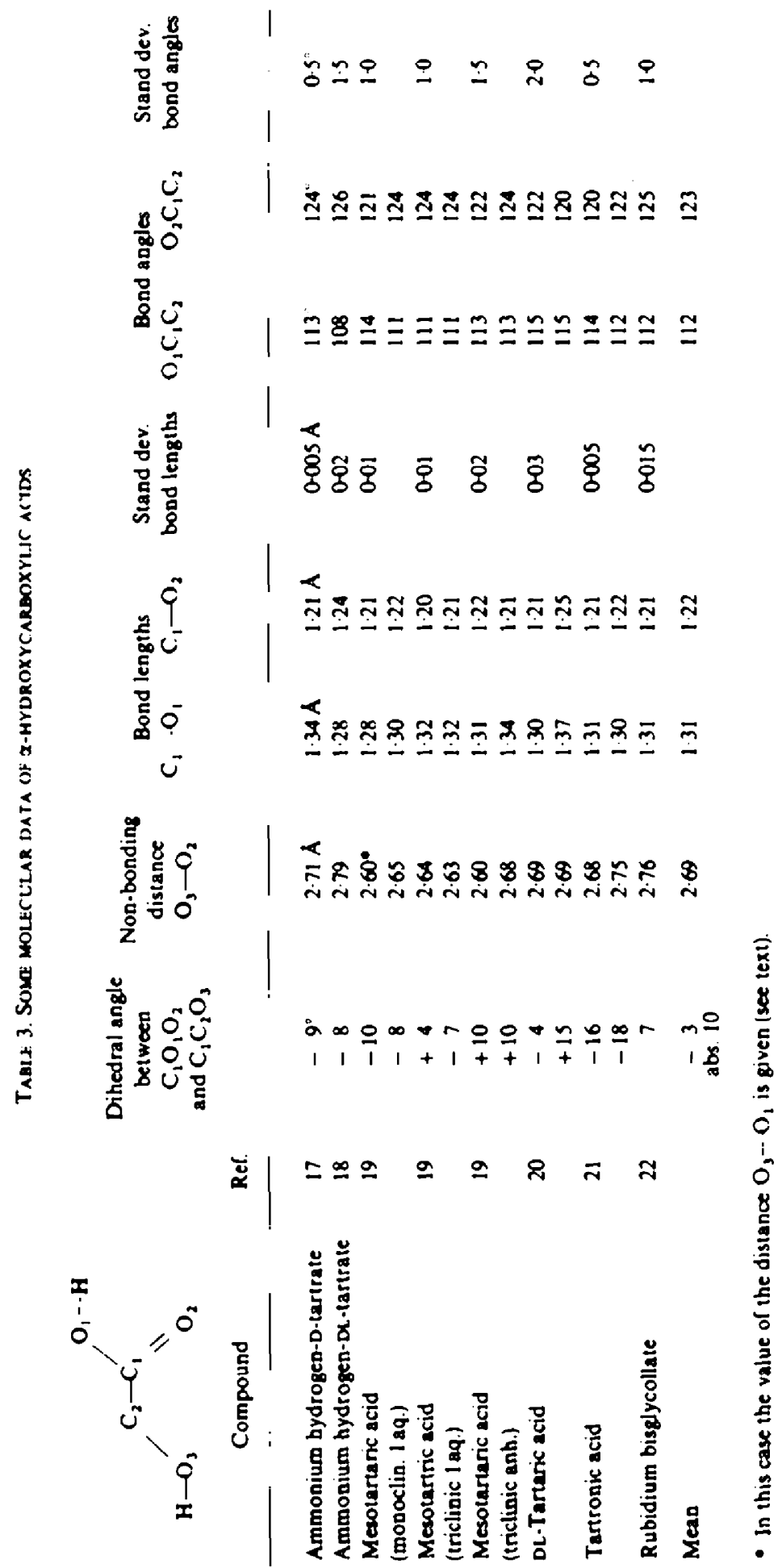




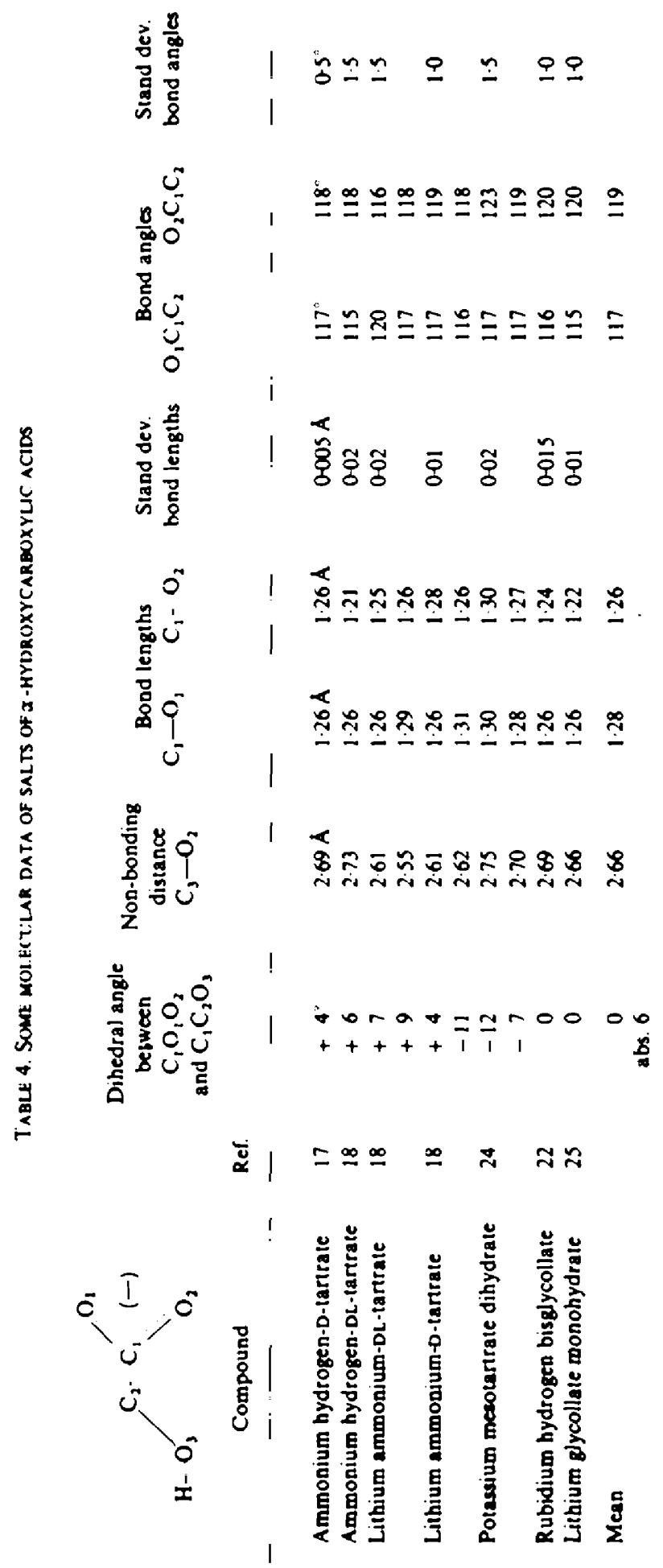

